\title{
Resident plant diversity and introduced earthworms have contrasting effects on the success of invasive plants
}

\author{
Timothy J. S. Whitfeld • Alexander M. Roth • \\ Alexandra G. Lodge • Nico Eisenhauer • \\ Lee E. Frelich $\cdot$ Peter B. Reich
}

Received: 14 September 2013/Accepted: 6 February 2014/Published online: 14 February 2014

(C) Springer International Publishing Switzerland 2014

\begin{abstract}
Theoretical predictions and empirical studies suggest that resident species diversity is an important driver of community invasibility. Through trait-based processes, plants in communities with high resident species diversity occupy a wider range of ecological niches and are more productive than low diversity communities, potentially reducing the opportunities for invasion through niche preemption. In terrestrial plant communities, biotic ecosystem engineers such as earthworms can also affect invasibility
\end{abstract}

Electronic supplementary material The online version of this article (doi:10.1007/s10530-014-0657-6) contains supplementary material, which is available to authorized users.

T. J. S. Whitfeld · A. M. Roth · A. G. Lodge .

L. E. Frelich · P. B. Reich

Department of Forest Resources, University of Minnesota, 1530 Cleveland Avenue North, St. Paul, MN 55108-6112, USA

Present Address:

T. J. S. Whitfeld ( $\square)$

Department of Ecology and Evolutionary Biology, Brown University, Box G-B225, 34 Olive St., Providence,

RI 02912, USA

e-mail:whitf015@umn.edu

\section{N. Eisenhauer}

Institute of Ecology, Friedrich-Schiller-University Jena, Dornburger Str. 159, 07743 Jena, Germany

\section{P. B. Reich}

Hawkesbury Institute for the Environment, University of Western Sydney, Penrith, NSW 2751, Australia by reducing leaf litter stocks and influencing soil conditions. In a greenhouse experiment, we simultaneously manipulated resident species diversity and earthworm presence to investigate independent and interactive effects of these two variables on the success of several invasive plants. Higher diversity of resident species was associated with lower biomass of invasives, with the effect mediated through resident species biomass. The presence of earthworms had a strong positive effect on the biomass of invasive species across all levels of resident species diversity and a weaker indirect negative effect via decreased soil moisture. Earthworms also weakened the positive correlation between resident species diversity and productivity. We did not observe any interactive effects of resident species biomass and earthworms on invasive species success. Partitioning the net biodiversity effect indicated that selection effects increased with resident species diversity whereas complementarity effects did not. Results suggest that managing for diverse forest communities may decrease the susceptibility of these communities to invasions. However, the presence of introduced earthworms in previously earthworm-free sites may undermine these efforts. Furthermore, future studies of plant community invasibility should account for the effects of introduced earthworms.

Keywords Biodiversity-ecosystem function . Functional diversity $\cdot$ Invasibility $\cdot$ Lumbricus terrestris $\cdot$ Rhamnus cathartica 


\section{Introduction}

The ecological consequences and economic impacts of invasive species have been documented by several generations of ecologists (Elton 1958; Vitousek et al. 1996; Davis et al. 2000; Pimentel et al. 2005; Gilliam 2007; Thuiller 2007; Corbin and D'Antonio 2012), but a predictive general synthesis of invasive species presence across the landscape remains elusive. Understanding why some communities are more susceptible to invasion than others could help inform management decisions that preempt or reduce the level of invasion at a given site. This is especially important as the pace of invasive species spread increases due to climate change and an expansion of human mobility (Vitousek et al. 1996; Pyšek et al. 2010), and because postinvasion control of these species is difficult and expensive.

Resident species diversity is one site characteristic predicted to affect the susceptibility of natural communities to invasion by introduced species (Elton 1958; Lodge 1993; Levine and D'Antonio 1999; Kennedy et al. 2002; Davis et al. 2005; Fridley et al. 2007). Diverse communities are hypothesized to have greater competition for light, space, and nutrients, and the theory of fluctuating resources suggests this should make them less susceptible to invasion (Davis et al. 2000). Whether or not this theoretical prediction is observed in natural communities is debatable, with previous studies reporting both negative (Brown and Peet 2003; Frankow-Lindberg 2012) and positive relationships (Cleland et al. 2004; Stohlgren et al. 2006) between resident species diversity and invasive species success. The spatial scale under investigation also complicates the question of how resident species richness affects invasibility, resulting in an "invasion paradox" (Knight and Reich 2005; Fridley et al. 2007). Patterns at the small scale tend to suggest a negative relationship while at larger scales the opposite may be true (Tilman 1997; Naeem et al. 2000; Kennedy et al. 2002; Knight and Reich 2005; Eschtruth and Battles 2009).

Species richness is a potentially important predictor of invasibility, but it accounts for only a portion of biological variation in a community (Srivastava et al. 2012). Communities may be composed of close relatives, distant relatives, or a mixture of the two so that not all groups of species with equal richness are functionally equivalent. Communities with high functional diversity may be able to use resources more effectively, leaving fewer unfilled "trait-niches" for potential invaders (Davis et al. 2000; CavenderBares et al. 2004; Eisenhauer et al. 2013). In addition, more functionally diverse communities tend to be more productive (Cadotte et al. 2008, 2009; Reich et al. 2012) because the taxa making up the community collectively capture a greater percentage of resources over space and time (Hooper et al. 2005), leaving less opportunity for invaders to establish.

Resident species richness and diversity are not the only factors determining the success of invasive species. Abiotic factors such as soil moisture, light levels, and disturbance also affect where invasive species are likely to be successful (Huston 2004). Heterogeneity in these factors may explain why, at large scales, resident species diversity is often positively related to invasive diversity (Knight and Reich 2005; Eschtruth and Battles 2009). These site characteristics may be influenced by large-scale environmental conditions and land use history, but can also be impacted by introduced biotic ecosystem engineers. Well-documented examples of ecosystem engineers are reviewed in Crooks (2002) and include the introduction of nitrogen fixing plants (Vitousek et al. 1987), rooting pigs (Singer et al. 1984), and, in formerly glaciated regions of North America, invasive earthworms (Frelich et al. 2006; Hendrix et al. 2008; Nuzzo et al. 2009). Earthworms cause a well documented cascade of ecological effects on soil microbial processes and biomass (Eisenhauer et al. 2011), water and nutrient cycling, soil structure, and seedbed conditions (McRill and Sagar 1973; Frelich et al. 2006; Eisenhauer et al. 2009), as well as decreasing soil moisture by forming preferential flow pathways (Shipitalo et al. 2004). The overall impact of these environmental changes is often a decline in diversity and cover of native plants (Hale et al. 2008) and potential large-scale "invasional meltdown" scenarios (Heimpel et al. 2010). Earthworms also influence community composition and plant demography by impacting competitive interactions between plant species in the short term (Wurst et al. 2005; Laossi et al. 2009) and long term (Laossi et al. 2011).

The overall impact of earthworm invasion depends on their ecological group, but their combined effects are significant enough to facilitate subsequent plant invasions (Eisenhauer et al. 2012a; Frelich et al. 2012). Direct links between earthworms and invasive 
plant abundance have been documented (Heneghan et al. 2007; Madritch and Lindroth 2009), and earthworm biomass is positively associated with invasive plant biomass (Nuzzo et al. 2009). The effects of earthworms and resident species diversity on invasive species success have been examined in isolation (e.g., Fridley et al. 2007; Wurst et al. 2011; Eisenhauer et al. 2012a) but their combined effects are only rarely documented (Eisenhauer et al. 2008). Both influence soil moisture and nutrients, so their combined effects may be additive, synergistic or antagonistic. To examine the possible interactive effects of earthworms and resident plant diversity on invasibility, we established a greenhouse-based microcosm experiment to mimic conditions in a temperate North American mesic hardwood forest community. We manipulated diversity of the experimental plant community and also the presence of earthworms to investigate the following questions: (1) Does increased resident plant diversity reduce the success of invaders? (2) Does the presence of earthworms increase the success of invaders? (3) Do earthworms and resident species diversity interactively affect the success of invaders?

\section{Methods}

\section{Experimental design}

We set up microcosms using PVC tubes with an inner diameter of $10 \mathrm{~cm}$, an area similar to the foraging zone of the anecic earthworm species used in this experiment (Nuutinen and Butt 2005), and height of $25 \mathrm{~cm}$. We taped $5 \mathrm{~mm}$ mesh to the bottom of each tube and added $5 \mathrm{~cm}$ of perlite to allow for drainage. A clear plastic sleeve (10 cm height) was taped to the top of each pot to prevent earthworms from escaping. The 138 microcosms were then filled to within $3 \mathrm{~cm}$ of the top with sieved and homogenized soil (DeMontreville loamy fine sand; texture: $69 \%$ sand, $23 \%$ silt, $8 \%$ clay; $\mathrm{pH}$ 5.06) collected from the surface layer of a nearby mesic hardwood forest. To mimic local growing season conditions, microcosms were placed in a greenhouse that was lit and heated with a day/ night regime of $16 / 8 \mathrm{~h}$ and $20 / 16{ }^{\circ} \mathrm{C}$. While smallscale microcosm studies are somewhat abstracted from reality, they provide a unique opportunity to isolate and explore potential mechanisms that may operate in nature. Their use in testing hypotheses related to ecosystem dynamics is well established (Partsch et al. 2006; Milcu et al. 2011; Eisenhauer et al. 2012b).

Before establishing the experimental communities of resident species, we kept the soil moist in the microcosms for 8 weeks and removed any seedlings germinating from the seedbank. The resident species communities consisted of different combinations of six herbaceous taxa including two legumes (Lathyrus sp., Desmodium glutinosum), two graminoids (Carex blanda, Elymus hystrix), and two non-leguminous forbs (Eurybia macrophylla, Asclepias exaltata). These taxa represent a functional cross section of herbaceous plants and were selected based on their high frequency and abundance in a 67-site vegetation field survey in the Eastern Broadleaf Forest province of Minnesota, USA (Whitfeld et al. 2013). We germinated the resident species from local seeds (Prairie Moon Nursery, Winona, Minnesota, USA) prior to the start of the experiment. Once established, we transplanted the seedlings into the microcosms. There was poor germination for two species (Lathyrus venosus and $L$. palustris), and too few seedlings of either species were available for them to be included individually. The two species belong to a well supported, recently diverged clade ( $\sim 2.5$ million years ago) nested within the genus Lathyrus (Schaefer et al. 2012). We felt justified in combining them in our analyses based on the assumption of niche conservatism (reviewed in Wiens et al. 2010) and because congeners are likely to be functionally similar with a high probability of being affected by comparable suites of biotic and abiotic influences (Gilbert et al. 2012).

Each microcosm contained six seedlings and was randomly assigned to one of four diversity treatments (Supplementary Material Table 1). Monoculture treatments contained six seedlings of one species (one functional group). Two different two-species treatments contained either three seedlings each of two species from the same functional group or three seedlings each of two species from different functional groups. Six-species treatments contained three functional groups, with one seedling per species. To allow the seedlings to establish in the microcosms, we maintained them for one month before starting the experiment.

A $3.5 \mathrm{~g}$ leaf litter layer, composed of sugar maple (Acer saccharum), basswood (Tilia americana), and 
northern red oak (Quercus rubra), collected from the same site as the soil and cut into pieces $1-2 \mathrm{~cm}$ long, was placed on the soil surface in each microcosm to simulate conditions in a natural community. We also added a single specimen of the invasive night-crawler (Lumbricus terrestris), purchased from Blue Ribbon Bait and Tackle Shop, Hugo, Minnesota, USA, to half of the microcosms in each diversity treatment. $L$. terretris is a burrowing anecic species that significantly impacts the leaf litter and soil processes we were investigating (Holdsworth et al. 2008). The earthworms were acclimated in buckets of the experimental soil for 2 weeks prior to the start of the experiment, a protocol used successfully in previous studies (Eisenhauer et al. 2012a). Once the microcosm communities, with earthworms and leaf litter, had established we added 10 seeds each of four invasive plants (common buckthorn, Rhamnus cathartica; Japanese barberry, Berberis thunbergii; garlic mustard, Alliaria petiolata; and dandelion, Taraxacum officinale) on top of the leaf litter to simulate seed rain in a natural community. Seeds of dandelion were purchased, but those of the other invasive species were collected from local forests.

The experiment ran for 9 weeks, giving the invasive species time to germinate and establish. Since we focused on germination and early establishment of invasive seedlings, this duration was reasonable, and avoided possible microcosm-effects on resident species' root growth. Each week, we randomized the position of the microcosms, and watered every other day with increasing volumes of deionized water (from 50 to $150 \mathrm{ml}$ ) as plant biomass increased. This standardized watering regime allowed us to measure treatment-induced differences in soil moisture, e.g., higher water uptake in microcosms with greater biomass of resident species and/or preferential flow through earthworm burrows.

\section{Harvest}

After 9 weeks we harvested aboveground biomass of all species in each microcosm and dried it at $70{ }^{\circ} \mathrm{C}$ for 3 days. Prior to harvest, we measured the light level (\% transmittance) at the soil surface in each microcosm (LI-190 quantum sensor, Licor). Following harvest of the aboveground biomass, we broke up the soil core in each microcosm and took a soil sample ( $\sim 60 \mathrm{~g}$ fresh weight) from the top $5 \mathrm{~cm}$ of the soil column. These samples were dried for 3 days at $70{ }^{\circ} \mathrm{C}$ and soil moisture was calculated by taking the difference between fresh and dry weight and dividing by dry weight. We rinsed all remaining soil from the roots and separated the shallow-rooted invasive seedlings from the deeper-rooted resident species. Roots were dried for 3 days at $70{ }^{\circ} \mathrm{C}$ then weighed. Since none of the garlic mustard seeds (invader species) germinated in the control or experimental microcosms despite cold stratification prior to the start of the experiment (Baskin and Baskin 1992), all analyses focus on the remaining three invasives. At least one buckthorn seed germinated in 103 of the 138 microcosms $(74.6 \%)$, whereas barberry seeds germinated in only 24 microcosms (17\%) and dandelion seeds in 35 $(25.3 \%)$. There were also unidentifiable emerging cotyledons of either buckthorn or barberry in 60 microcosms $(43.5 \%)$.

\section{Analyses}

We performed ANOVAs to investigate the effects of resident species diversity, earthworms (presence/ absence), and the interaction of diversity and earthworms on total invasive species biomass, total resident species biomass, percent light transmittance, and soil moisture. As resident species diversity incorporated variation in species number and functional group, diversity was characterized by four nominal treatments ranging from least to most diverse (1 species and 1 functional group, 2 species and 1 functional group, 2 species and 2 functional groups, 6 species and 3 functional groups). We compared mean values with Tukey's HSD test. Although our statistical analyses addressed effects of earthworm treatments, plant diversity treatments, and their interaction, given the focus on understanding and contrasting their effects, we largely present results visually (in figures) separated by earthworm treatments.

We included all predictor variables (resident species diversity, earthworm presence/absence, resident species aboveground biomass, light transmittance, soil moisture, remaining litter dry weight) in a general linear model (GLM) to examine their combined effects on invasive species biomass. Because we were interested in potential ecological interactions between earthworms and resident species diversity we included the interaction term for these two variables in addition to interaction terms for earthworms and all other 
measured variables (except leaf litter which we predicted would not change in microcosms without earthworms). The best-fit model was chosen based on minimum Akaike Information Criteria (AIC) scores. ANOVA and GLM analyses were performed using JMP ver. 9.0.2 (SAS Institute, Inc., Cary, NC, USA).

Path analysis allowed us to simultaneously examine potential direct and indirect relationships between resident species diversity, earthworm presence/ absence (exogenous variables) and their effects on total invasive species biomass (endogenous variable). Earthworm presence/absence was included in the path analysis as a dichotomous categorical predictor. It functions in the path diagram similar to a factor variable in a standard regression model (Hoyle 2012), represented as 0 when earthworms were absent and 1 when earthworms were present. The resulting path estimate is therefore the effect when earthworms were present, and would be zero when earthworms were absent. The four levels of diversity were arranged in order of increasing overall diversity (monoculture $=1$; two species/one functional group $=2$; two species/two functional groups $=3$; six species $=4$ ) and treated as a continuous variable in the path analysis. While other statistical methods do exist for treating ordinal variables differently in path analysis, for large numbers of categories (four or more), the literature suggests that treatment of ordinal variables as continuous is reasonable (Bentler and Chou 1987; Byrne 2010). Our initial model (Supplementary Material Figure S1) was based on prior knowledge and observations from ANOVA analyses. Furthermore, we tested the indirect relationships of the exogenous variables via total resident species biomass and soil moisture. Model fits were determined by nonsignificant Chi squared tests $(P>0.05)$ and AIC scores (Grace 2006; Arbuckle 2012). We used stepwise removal of unimportant variables to improve the model fit based on the indices mentioned above. We retained only relationships with a plausible ecological basis. Path analyses were performed in Amos 5 (Amos Development Corporation, Crawfordsville, FL, USA).

To assess the overall effect of diversity on productivity we partitioned the net diversity effect of the two different two-species treatments and the six-species treatment into selection and complementarity effects with the additive partitioning biodiversity effect equation (Loreau and Hector 2001). The selection effect is quantified as the covariance function relating yield of a species in a mixture with its yield in monoculture, and acts through interspecific competition leading to dominance of certain species with particular traits (Loreau and Hector 2001). A positive selection effect indicates that the most productive species in monoculture overyielded in mixtures and so benefits more from inter- rather than intraspecific interactions (Reich et al. 2012). Complementarity effects measure changes in the average relative yield in a species mixture (Loreau and Hector 2001; Byun et al. 2013), and are related to niche differentiation or facilitation that lead to positive species interactions in mixed communities (e.g., Reich et al. 2012). These calculations were performed in $\mathrm{R}$ version 2.15.3 ( $\mathrm{R}$ Development Core Team 2009) based on code originally written for analysis in Reich et al. (2012).

\section{Results}

By the end of the experiment, leaf litter biomass and soil moisture were significantly lower in microcosms with earthworms (29 and $21 \%$ lower respectively) indicating that earthworms were active during the course of the experiment despite $82 \%$ earthworm mortality by its end. Based on weekly observations of earthworm activity (casts/middens), continuously declining leaf litter until the end of the experiment, and the presence of partially decomposed earthworms we were able to verify that the mortality occurred during a heat wave over the last 3 days of the experiment, which the cooling system in the greenhouse was unable to mitigate. It is possible that the dead earthworms released a pulse of nutrients but since the mortality occurred in the last days of the experiment effects on either resident or invasive plants is likely to have been minimal. In control pots (which did not contain earthworms, resident species, or leaf litter), common buckthorn, barberry, and dandelion (invader species) germinated at rates of 90, 80, and $64 \%$ respectively.

As our resident diversity treatments included variation in both species richness and functional group richness, they are considered nominal for analyses. There were significant relationships between resident species diversity and percent light transmittance, percent soil moisture, and the total biomass (root and shoot) of both resident species and invasive species (Table 1). Earthworm presence was related to invasive 
Table 1 Analysis of variance to examine the effects of resident species diversity, earthworms, and the interaction of diversity and earthworms on resident species biomass, invasive species biomass, soil moisture, and light transmittance

\begin{tabular}{|c|c|c|c|c|c|c|}
\hline & \multicolumn{2}{|c|}{ Resident species diversity } & \multicolumn{2}{|c|}{ Earthworms present/absent } & \multicolumn{2}{|c|}{ Resident diversity $\times$ earthworms } \\
\hline & $F_{(1,1)}$ & $\mathrm{P}$ & $F_{(1,1)}$ & $\mathrm{P}$ & $F_{(1,1)}$ & $\mathrm{P}$ \\
\hline Resident species biomass & 27.51 & $<0.0001$ & 2.25 & 0.14 & 1.20 & 0.28 \\
\hline Invasive species biomass & 37.54 & 0.0001 & 37.54 & $<0.0001$ & 0.03 & 0.85 \\
\hline Percent light transmittance & 5.56 & 0.02 & 1.82 & 0.18 & 1.06 & 0.30 \\
\hline Soil moisture & 27.52 & $<0.0001$ & 11.96 & 0.0007 & 0.001 & 0.97 \\
\hline
\end{tabular}

Significant relationships are indicated in bold. Resident species include graminoids (Carex blanda, Elymus hystrix), legumes (Lathyrus sp., Desmodium glutinosum), and non-leguminous forbs (Eurybia macrophylla, Asclepias exaltata)

species biomass and soil moisture but we observed no significant interactions between resident species diversity or earthworms and the measured variables (Table 1).

Total biomass (root and shoot) of resident species increased with diversity and was unaffected by earthworms (Table 1; Fig. 1a). There was also no interactive effect of earthworm presence/absence and resident species diversity on the total biomass of resident species (Table 1). By contrast, total invasive species biomass decreased with higher resident diversity and increased markedly (by $100 \%$ across all diversity treatments) in the presence of earthworms (Table 1; Fig. 1b) although there was no interaction between earthworms and resident species diversity (Table 1). We observed no difference in the success of invasive species in monocultures of the two Lathyrus species $\left(F_{(3,8)}=1.02, P=0.43\right)$ suggesting their effects on invasive species' establishment were similar. Across all diversity treatments, those containing a graminoid species (Carex blanda or Elymus hystrix) had higher biomass than those without graminoids. This was true whether earthworms were present $\left(F_{(1,67)}\right.$ $=113.77, P<0.0001)$ or absent $\left(F_{(1,67)}=117.56\right.$, $P<0.0001)$. Mean biomass, by earthworm treatment, of each invasive and resident species is presented in the Supplementary Material (Fig. S2).

We also examined the relationship between total invasive and resident species biomass across all microcosms (Fig. 2). These variables showed a highly significant negative relationship (earthworms absent: $F_{(1,67)}=42.39, P<0.0001$; earthworms present $\left.F_{(1,67)}=39.18, P<0.0001\right)$, and additionally, invasive biomass at any given level of resident biomass was higher in the presence of earthworms $\left(F_{(3,134)}=70.11, P<0.0001\right)$ (Fig. 2). Moreover, invasive species germinated in all but one microcosm containing earthworms. By contrast, 20 of the 69 microcosms $(28 \%)$ without earthworms had no invasive species germination. In addition, across all levels of resident species diversity, root biomass was higher for invasive species when earthworms were present $\left(F_{(1,136)}=14.44, P=0.0002\right)$, but this was not the case for resident species $\left(F_{(1,136)}=0.01\right.$, $P=0.93)$. At the same time, due to the increase in aboveground biomass, the root-to-shoot ratio of invasive species decreased in the presence of earthworms $\left(F_{(1,115)}=7.37, P=0.008\right)$, and was marginally lower for resident species $\left(F_{(1,136)}=3.20\right.$, $P=0.08)$. We also observed higher germination rates of invasives (i.e., the number of seedlings) across all levels of resident species diversity when earthworms where present $\left(F_{(3,} 134\right)=341.74$, $P<0.0001)$.

Because we were interested in the effects of resident plant diversity on a suite of common herbaceous and woody invasive species we report results that combined the biomass of all invasive species. Common buckthorn was the most successful invasive species so we also analyzed the treatment effects on this species alone and found similar results. The biomass of barberry and dandelion alone also decreased as resident species diversity increased $\left(F_{(7,136)}=3.83, P=0.0115\right)$ but the presence of earthworms did not influence their success.

GLM suggested that the best-fit model $\left(\mathrm{R}^{2}=0.58\right)$ predicting invasive species biomass included total resident species biomass together with the effects of earthworms and soil moisture. Also included in the model were interaction terms between earthworms and soil moisture, and earthworms and light transmittance (Table 2). A model with only resident species biomass, earthworms, and soil moisture explained $54 \%$ of the variance in 

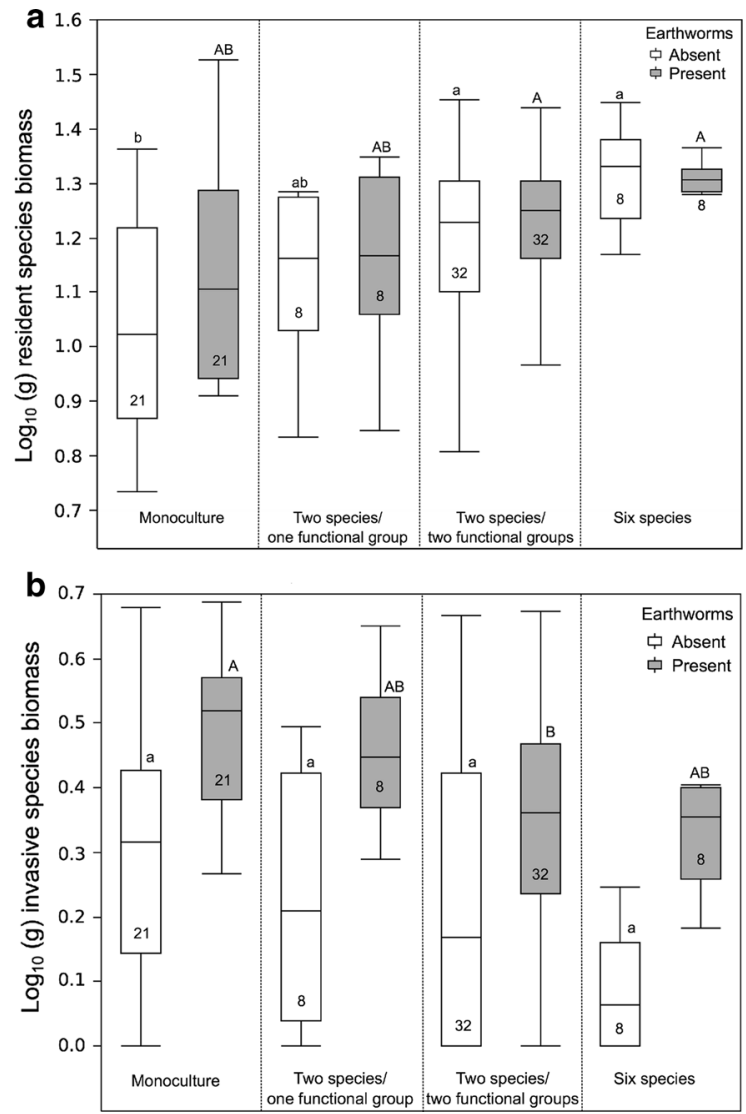

Fig. 1 Separate one way analyses of variance to examine a the effects of resident species diversity on total resident species biomass (earthworms absent: $F_{(3,65)}=6.27, P=0.0008$; earthworms present: $\left.F_{(3,65)}=3.33, P=0.02\right)$ and $\mathbf{b}$ the effects of resident species diversity on total invasive species biomass (earthworms absent: $F_{(3,65)}=2.18, P=0.10$; earthworms present: $\left.F_{(3,65)}=4.29, P=0.008\right)$. Filled and open bars (with sample sizes) represent microcosms with and without earthworms respectively $( \pm \mathrm{SE})$. Across diversity levels, within each earthworm treatment, bars labeled with different letters (earthworms absent $=$ lower case, earthworms present $=$ upper case) are significantly different from one another. Resident species include graminoids (Carex blanda, Elymus hystrix), legumes (Lathyrus sp., Desmodium glutinosum), and nonleguminous forbs (Eurybia macrophylla, Asclepias exaltata)

invasive biomass, indicating the importance of these variables in this model.

Path analysis supported results from the ANOVA and GLM and indicated possible mechanisms for the observed effects of resident species functional diversity on invasive species success. The initial model (Supplementary Material Figure S1) fitted the data $\left(\chi_{6}^{2}=7.39, P=0.29 ;\right.$ AIC $\left.=51.39\right)$ but could be improved. The final model (Fig. $3, \chi_{2}^{2}=0.139$,

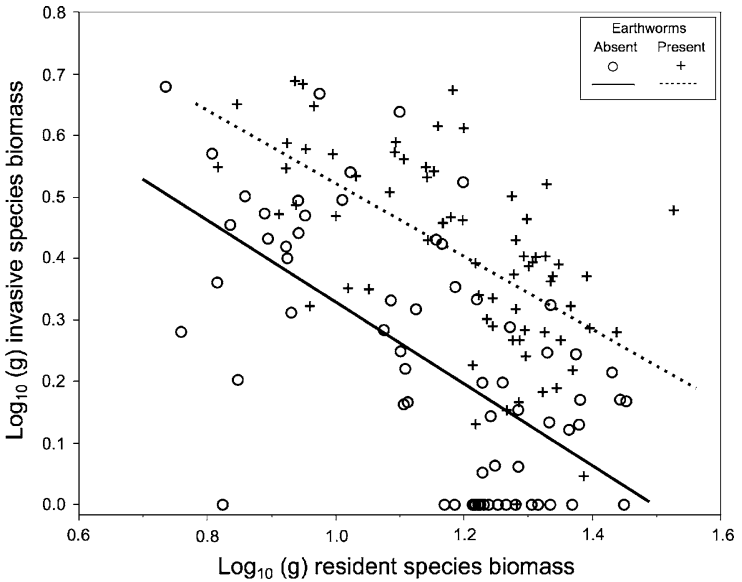

Fig. 2 Resident species biomass versus invasive species biomass with (dashed line) and without earthworms (solid line). Resident species include graminoids (Carex blanda, Elymus hystrix), legumes (Lathyrus sp., Desmodium glutinosum), and non-leguminous forbs (Eurybia macrophylla, Asclepias exaltata). Open circles $=$ earthworms absent, $\left.\mathrm{R}^{2}=0.39, F_{(1,67)}=42.39, P<0.0001\right) ;$ crosses $=$ earthworms present, $\mathrm{R}^{2}=0.37, F_{(1,67)}=39.18, P<0.0001$

Table 2 General linear model predicting invasive species biomass in 138 microcosm communities with varying resident species diversity

\begin{tabular}{llll}
\hline & SS & $F$ & $P$ \\
\hline Earthworms & 1.80 & 33.90 & $\mathbf{< 0 . 0 0 0 1}$ \\
Total resident species biomass & 0.43 & 24.24 & $\mathbf{< 0 . 0 0 0 1}$ \\
Soil moisture & 0.36 & 10.14 & $\mathbf{< 0 . 0 0 0 1}$ \\
Resident species diversity & 0.004 & 0.24 & 0.62 \\
Light transmittance & 0.001 & 0.06 & 0.80 \\
Litter mass & 0.03 & 1.78 & 0.18 \\
Soil moisture $\times$ earthworms & 0.14 & 8.28 & $\mathbf{0 . 0 0 5}$ \\
Light transmittance $\times$ earthworms & 0.09 & 4.82 & $\mathbf{0 . 0 3}$ \\
Resident species & 0.03 & 0.88 & 0.62 \\
$\quad$ diversity $\times$ earthworms & & & \\
Total resident species & 0.01 & 0.67 & 0.41 \\
biomass $\times$ earthworms & & & \\
\hline
\end{tabular}

Best-fit model was chosen based on minimum AIC scores. Total $\mathrm{R}^{2}=0.58$. Significant relationships are indicated in bold. Functional groups include graminoids (Carex blanda, Elymus hystrix), legumes (Lathyrus sp., Desmodium glutinosum), and non-leguminous forbs (Eurybia macrophylla, Asclepias exaltata)

$P=0.93 ;$ AIC $=26.14)$ indicated that resident species diversity had a significant negative effect on invasive species biomass via total resident species biomass and soil moisture. Earthworms had a direct positive effect on invasive species biomass, and a 


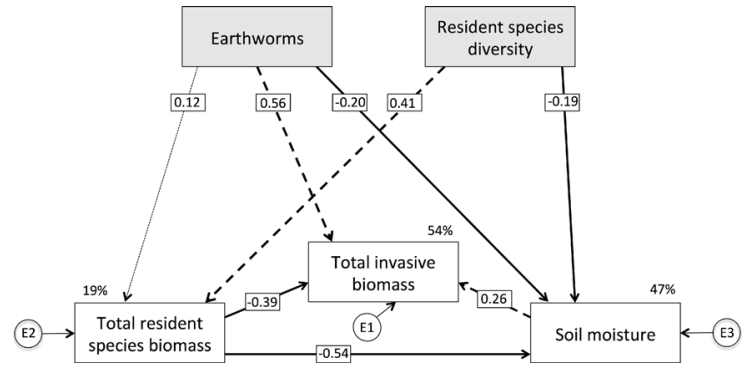

Fig. 3 Best-fit path analysis of causal influences of earthworm presence/absence and resident plant species functional diversity (exogenous variables) on total invasive plant species biomass, soil moisture, and total resident plant species biomass (endogenous variables). Numbers on arrows are standardized path coefficients (equivalent to correlation coefficients). Solid and dashed lines indicate negative and positive relationships respectively. Bold lines indicate significant standardized path coefficients $(P<0.05)$, and the fine dashed line indicates nonsignificant path coefficient $(P>0.05)$. Circles indicate error terms (E1-E3). Model fitted the data: Chi square $=0.106$, probability level $=0.948$, AIC $=26.106$

weaker, indirect negative effect via decreased soil moisture. We found similar effects when biomass of buckthorn alone was considered (Supplementary Material Figure S1). By partitioning the net biodiversity effect (Fig. $4 \mathrm{a}-\mathrm{c}$ ), we found the positive relationship between resident species diversity and biomass was due to a significant, positive selection effect (Fig. 4c). The net biodiversity effect and selection effect increased as invasive biomass decreased (Supplementary Material Figure S3). These relationships were mediated through resident species biomass (Supplementary Material Figure S4), which was correlated with resident species diversity (Fig. 1).

\section{Discussion}

Experimental manipulation of resident species diversity and the presence or absence of earthworms resulted in varied effects on the success of invading plants. Below we address the following questions pertinent to those findings.

Question 1: Does increased resident plant functional diversity reduce the success of invaders?

Invasive plant biomass and abundance were lower in microcosms with higher resident plant diversity and biomass, suggesting that resident diversity does influence both the germination and establishment of invaders. This supports theoretical predictions of the diversity resistance hypothesis (Elton 1958; Case 1990), and results of previous studies investigating similar, fine-scale relationships (Tilman 1997; Naeem et al. 2000; Kennedy et al. 2002; Brown and Peet 2003; Frankow-Lindberg 2012). The effect of increasing resident species richness is normally explained in terms of greater resource use in more diverse communities (Davis et al. 2000) leading to higher productivity (Cadotte et al. 2009; Tilman et al. 2012) that leaves invaders with fewer opportunities to be successful.

Our study indicates that increased resident plant diversity was positively related to total resident species biomass. By partitioning this net biodiversity effect into complementarity and selection effects we were able to examine possible mechanisms driving the pattern. The observed increase in selection effects with increasing diversity suggests one or more species were dominating the six species microcosms (Cardinale et al. 2006). In fact, across all diversity treatments, microcosms containing a graminoid species (Carex blanda or Elymus hystrix) had higher biomass than those without graminoids, whether or not earthworms were present, and these species appear to be driving the observed selection effect. By contrast, similar microcosm studies (Eisenhauer et al. 2012b; Byun et al. 2013) concluded that complementarity effects were more important than selection effects, and this pattern was also observed in previous large scale plot studies (Loreau and Hector 2001; Reich et al. 2012). Our results suggest the diversity effect was mediated through resident species biomass (indicated by the path analysis) that was strongly influenced by the graminoid species we included. The experimental design we used may have influenced the observed selection effects, and future studies with different resident species would be useful to determine whether or not this is the case. However, it is likely that higher resident species diversity in a natural plant community would increase the likelihood of there being some species that will have this effect (Levine and D'Antonio 1999). The effects we observed were focused on the early stages of invader success because we were interested in this potential bottleneck stage of invasive species establishment. A longer-term approach would be required to test whether the effects of resident species diversity persist (Laossi et al. 2011). 

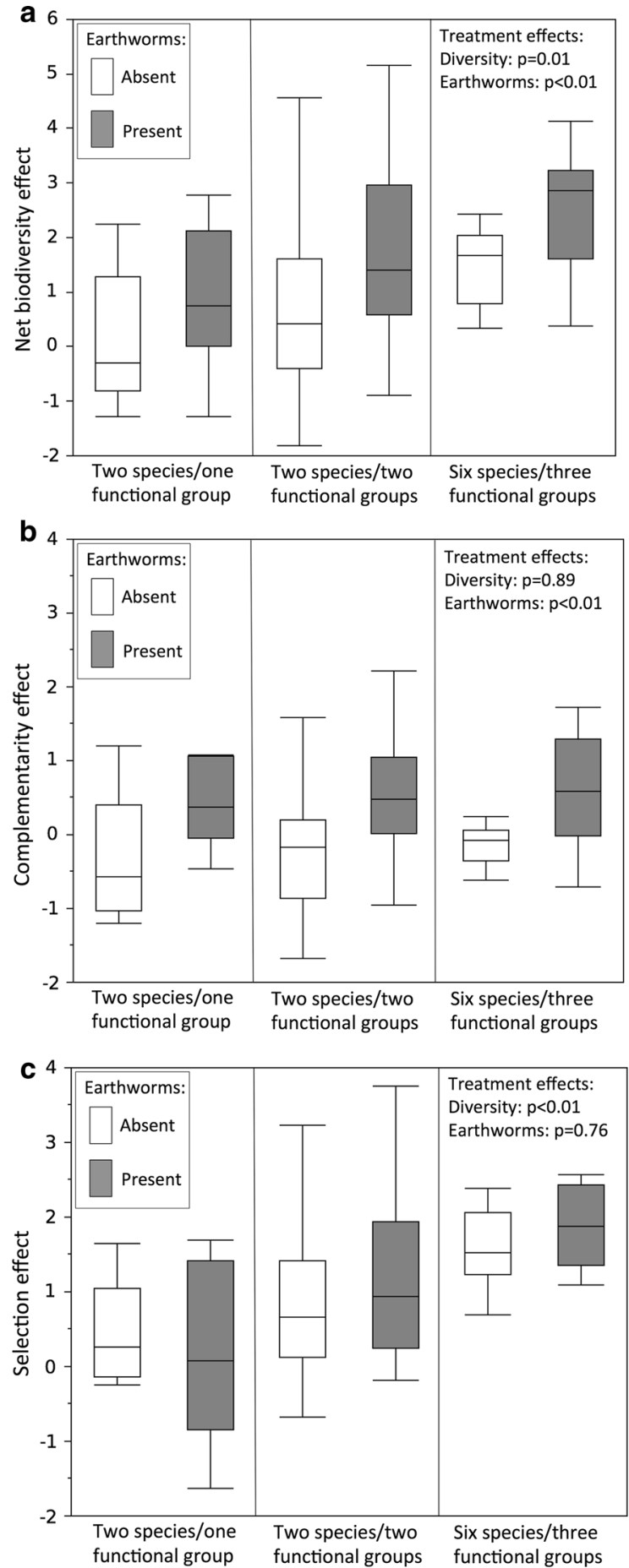

Fig. 4 One-way analysis of variance to examine a net biodiversity effects, b complementarity effects, and c selection effects across three levels of resident species diversity, with and without earthworms (gray bars/white bars respectively). $P$ values reflect significance tests for the main effects of diversity and earthworms (presence/absence). Interaction terms were not significant in any case
Question 2: Does the presence of earthworms increase the success of invaders?

Invasive species successfully germinated in all but one of the microcosms that contained earthworms (indicated by the single " + " in the zero gram invasive biomass on Fig. 2). Furthermore, across all levels of resident plant diversity, invader biomass and abundance were higher when earthworms were present, supporting the hypothesis that earthworms promote the germination and establishment of invaders. Conversely, the effect of earthworms on resident species included in the experiment was neutral with the exception of Elymus hystrix, which had slightly higher biomass in monocultures in the presence of earthworms. In natural plant communities, the presence of earthworms may benefit a subset of resident plant species, particularly grasses and sedges (Nuzzo et al. 2009) that may be pre-adapted by chance to earthworm-induced environmental conditions. Earthworms also positively influenced grasses in previous microcosm studies (Wurst et al. 2005; Laossi et al. 2009), suggesting a relationship worthy of more detailed investigation.

The best-fit GLM to explain the success of invasive species included the presence of earthworms. In addition, path analysis indicated a direct (unexplained), positive effect of earthworms on invasive species biomass that was stronger than the indirect negative impact that arose via changes in soil moisture. Our analyses indicated that the success of invasive plants was related to the presence of earthworms. The increase in total invasive species biomass (roots and shoots) in the presence of earthworms (even at the highest level of resident species diversity) suggests these belowground invaders may diminish the resistance to invasion that arises from higher resident species diversity. As a result, management efforts that seek to maximize resident plant diversity may be undermined by the ubiquitous presence of invasive earthworms that simultaneously reduce resident plant richness in natural communities (Holdsworth et al. 2007) and increase invader success.

The positive relationship between earthworms and success of the invasive plant species in our experiment may have occurred because the introduced plants have a long history of co-evolution with earthworms (Forey et al. 2011). These species can take advantage of the post-earthworm invasion environment that includes reduced leaf litter and increased bare mineral soil. Plant 
species that evolved outside the influence of earthworms often require an organic duff layer for germination, making them less successful in sites where earthworms are now present (Frelich et al. 2006).

Earthworms are also known to impact seeds and seedling survival in other ways (reviewed in Forey et al. 2011). They can influence long-term germination rates through maternal effects (Laossi et al. 2010) and by moving seeds below the soil surface, thereby reducing the chances of seed predation and desiccation (Azcarate and Peco 2006). It should also be mentioned that earthworms might reduce germination if the seeds are moved below a critical depth (Thompson et al. 1994) and negative effects have also been documented in very small-seeded species (McCormick et al. 2013). In addition, their castings provide nutrient rich mineral soil substrate for germinating invasive seeds (Eisenhauer and Scheu 2008), a phenomenon we observed in the greenhouse microcosms and in nearby field sites. Earthworms may have also influenced competitive interactions and relative growth rates of the included plants even though this was a short-term experiment (Wurst et al. 2005; Laossi et al. 2009). The effects we observed do not necessarily reflect long term impacts of earthworms on natural plant communities if earthworms affect fecundity and germination of plants as predicted by Laossi et al. (2009). As with the patterns related to resident species diversity, longer-term experiments or observations are required to examine whether earthworm effects on invasive species persist.

Another noteworthy result from this study is that despite observing no significant change in the complementarity effect as resident species diversity increased, earthworms did significantly increase this component of net biodiversity by $300 \%$ across all diversity treatments (Fig. 4). The net biodiversity effect also increased in the presence of earthworms by $155 \%$, whereas the selection effect was not significantly affected. A possible mechanism for the observed increase in net and complementarity biodiversity effects might include earthworms' positive impact on nutrient availability (Eisenhauer 2012).

Question 3: Do earthworms and resident species diversity interactively affect the success of invaders?

Since earthworms and resident species diversity both influence soil moisture and nutrients their combined effects may be additive, synergistic or antagonistic. We observed a negative effect of resident species diversity on invasive species success, but the impact of earthworms on this relationship was similar across all levels of diversity and there was no interaction between these two variables. Previous studies have found significant, interactive effects on plant community composition when earthworms and warming treatments were combined (Eisenhauer et al. 2012a). Others have predicted synergistic effects on plant community invasibility from deer herbivory and earthworms (Frelich et al. 2006). That we observed no interacting effects of earthworms and resident species diversity-despite significant independent effects-may reflect the inherent limitations of microcosm studies such as this, indicate that interactions occurs via long-term field processes, or both. Other longer term studies report earthworms facilitate invasion at intermediate levels of resident plant diversity but not under monoculture or high diversity conditions (Eisenhauer et al. 2008). Since we observed independent impacts of resident plant diversity and earthworms on the same processes (plant biomass and soil moisture), interactions may develop over a longer time. Also in the longer term, resident plant diversity may influence earthworm performance (Eisenhauer et al. 2008) initiating feedbacks that affect plant community performance and invasibility.

Despite the lack of interaction between earthworms and resident species biomass, we did observe interactions between soil moisture and earthworms as well as light transmittance and earthworms. The difference in invasive species biomass between earthworm treatments was highest at low levels of soil moisture (high species diversity) and high soil surface light levels (low species diversity). In both cases, the tendency for earthworms to bury seeds is likely to reduce desiccation and so increase invasive species germination. Earthworms also provide moist soil in castings around their burrows where we observed much of the invasive species germination. Taken together, these interactions suggest that earthworm activity will benefit invasive species across all levels of resident species diversity through interactions with multiple environmental factors.

A fruitful avenue for future research would be to examine natural communities across full factorial combinations of earthworm abundance and resident species diversity gradients. However, this approach is 
difficult in practice because sites with low earthworm abundance are virtually non-existent in the Upper Midwest, USA.

In conclusion, we demonstrated that resident species diversity and earthworms have opposing influences on a bottleneck stage of invasive plant establishment. Furthermore, our results suggest the ubiquitous presence of earthworms may undermine the possible reduction in plant community invasibility conferred by high resident species diversity. The results of our experiment provide insights into the combined effects of resident species diversity and earthworms on invasive plants. Based on our results, it is also clear that future studies of plant community invasibility in previously earthworm free regions of North America should account for the effects of introduced earthworms.

Acknowledgments We thank Cindy Buschena and Susan Barrott for their help during the experiment and Forest Isbell for assistance with data analysis. Also, we thank the two anonymous reviewers whose comments helped improve the manuscript. In addition, we thank Warner Nature Center for allowing us to collect soil and leaf litter for the experiment. For assistance during the experiment we thank the undergraduate student workers in the Reich lab. This project was supported by a grant from the Legislative Citizen Commission on Minnesota Resources (M.L. 2010, Chp. 362, Sect. 2, Subd. 6c "Healthy Forests to Resist Invasion," to PBR). Support was also provided by the Integrative Graduate Education and Research Traineeship: Risk Analysis for Introduced Species and Genotypes (NSF DGE-0653827); University of Minnesota Graduate School; the Wilderness Research Foundation; and the Dayton Fund of the Bell Museum of Natural History. NE gratefully acknowledges funding by the Deutsche Forschungsgemeinschaft (DFG; Ei 862/1, Ei 862/2).

\section{References}

Arbuckle JL (2012) IBM SPSS Amos 19 user's guide. Amos Development Corporation, Crawfordsville

Azcarate FM, Peco B (2006) Effects of seed predation by ants on Mediterranean grassland related to seed size. J Veg Sci 17:353-360

Baskin JM, Baskin CC (1992) Seed germination biology of the weedy biennial Alliaria petiolata. Nat Areas J 12:191-197

Bentler PM, Chou C (1987) Practical issues in structural modeling. Sociol Method Res 16:78-117

Brown RL, Peet RK (2003) Diversity and invasibility of southern Appalachian plant communities. Ecology $84: 32-39$

Byrne BM (2010) Structural equation modeling with AMOS: basic concepts, applications, and programming, 2nd edn. Routledge, New York
Byun C, de Blois S, Brisson J (2013) Plant functional group identity and diversity determine biotic resistance to invasion by an exotic grass. J Ecol 101:128-139

Cadotte MW, Cardinale BJ, Oakley TH (2008) Evolutionary history and the effect of biodiversity on plant productivity. Proc Natl Acad Sci USA 105:17012-17017

Cadotte MW, Cavender-Bares J, Tilman D et al. (2009) Using phylogenetic, functional and trait diversity to understand patterns of plant community productivity. PLoS ONE 4

Cardinale BJ, Srivastava DS, Duffy JE et al (2006) Effects of biodiversity on the functioning of trophic groups and ecosystems. Nature 443:989-992

Case TJ (1990) Invasion resistance arises in strongly interacting species-rich model competition communities. Proc Natl Acad Sci USA 87:9610-9614

Cavender-Bares J, Ackerly DD, Baum DA et al (2004) Phylogenetic overdispersion in Floridian oak communities. Am Nat 163:823-843

Cleland EE, Smith MD, Andelman SJ et al (2004) Invasion in space and time: non-native species richness and relative abundance respond to interannual variation in productivity and diversity. Ecol Lett 7:947-957

Corbin JD, D'Antonio CM (2012) Gone but not forgotten? Invasive plants' legacies on community and ecosystem properties. Invasive Plant Sci Manag 5:117-124

Crooks JA (2002) Characterizing ecosystem-level consequences of biological invasions: the role of ecosystem engineers. Oikos 97:153-166

Davis MA, Grime JP, Thompson K (2000) Fluctuating resources in plant communities: a general theory of invasibility. J Ecol 88:528-534

Davis MA, Thompson K, Grime JP (2005) Invasibility: the local mechanism driving community assembly and species diversity. Ecography 28:696-704

Eisenhauer N (2012) Aboveground-belowground interactions as a source of complementarity effects in biodiversity experiments. Plant Soil 351:1-22

Eisenhauer N, Scheu S (2008) Invasibility of experimental grassland communities: the role of earthworms, plant functional group identity and seed size. Oikos 117:1026-1036

Eisenhauer N, Milcu A, Sabais ACW et al (2008) Animal ecosystem engineers modulate the diversity-invasibility relationship. PLoS ONE 3:e3489

Eisenhauer N, Schuy M, Butenschoen O et al (2009) Direct and indirect effects of endogeic earthworms on plant seeds. Pedobiologia 52:151-162

Eisenhauer N, Schlaghamerský Reich P et al (2011) The wave towards a new steady state: effects of earthworm invasion on soil microbial functions. Biol Invasions 13:2191-2196

Eisenhauer N, Fisichelli NA, Frelich LE et al (2012a) Interactive effects of global warming and 'global worming' on the initial establishment of native and exotic herbaceous plant species. Oikos 121:1121-1133

Eisenhauer N, Reich PB, Isbell F (2012b) Decomposer diversity and identity influence plant diversity effects on ecosystem functioning. Ecology 93:2227-2240

Eisenhauer N, Schulz W, Scheu S et al (2013) Niche dimensionality links biodiversity and invasibility of microbial communities. Funct Ecol 27:282-288

Elton CS (1958) The ecology of invasions by animals and plants. Metheun \& Co., London 
Eschtruth AK, Battles JJ (2009) Assessing the relative importance of disturbance, herbivory, diversity, and propagule pressure in exotic plant invasion. Ecol Monogr 79:265-280

Forey E, Barot S, Decaens T et al (2011) Importance of earthworm-seed interactions for the composition and structure of plant communities: a review. Acta Oecol Int J Ecol 37:594-603

Frankow-Lindberg B (2012) Grassland plant species diversity decreases invasion by increasing resource use. Oecologia 169:793-802

Frelich L, Hale C, Scheu S et al (2006) Earthworm invasion into previously earthworm-free temperate and boreal forests. Biol Invasions 8:1235-1245

Frelich LE, Peterson RO, Dovçiak M et al (2012) Trophic cascades, invasive species and body-size hierarchies interactively modulate climate change responses of ecotonal temperate-boreal forest. Philos Trans R Soc B Biol Sci 367:2955-2961

Fridley JD, Stachowicz JJ, Naeem S et al (2007) The invasion paradox: reconciling pattern and process in species invasions. Ecology 88:3-17

Gilbert GS, Magarey R, Suiter K et al (2012) Evolutionary tools for phytosanitary risk analysis: phylogenetic signal as a predictor of host range of plant pests and pathogens. Evol Appl 5:869-878

Gilliam FS (2007) The ecological significance of the Herbaceous Layer in temperate forest ecosystems. Bioscience $57: 845-858$

Grace JB (2006) Structural equation modeling and natural systems. Cambridge University Press, Cambridge

Hale C, Frelich L, Reich P et al (2008) Exotic earthworm effects on hardwood forest floor, nutrient availability and native plants: a mesocosm study. Oecologia 155:509-518

Heimpel G, Frelich L, Landis D et al (2010) European buckthorn and Asian soybean aphid as components of an extensive invasional meltdown in North America. Biol Invasions 12:2913-2931

Hendrix PF, Callaham MA, Drake JM et al. (2008) Pandora's box contained bait: the global problem of introduced earthworms. Annual review of ecology evolution and systematics. Annual Reviews, Palo Alto, pp 593-613

Heneghan L, Steffen J, Fagen K (2007) Interactions of an introduced shrub and introduced earthworms in an Illinois urban woodland: Impact on leaf litter decomposition. Pedobiologia 50:543-551

Holdsworth AR, Frelich LE, Reich PB (2007) Effects of earthworm invasion on plant species richness in northern hardwood forests. Conserv Biol 21:997-1008

Holdsworth AR, Frelich LE, Reich PB (2008) Litter decomposition in earthworm-invaded northern hardwood forests: role of invasion degree and litter chemistry. Ecoscience 15:536-544

Hooper DU, Chapin FS, Ewel JJ et al (2005) Effects of biodiversity on ecosystem functioning: a consensus of current knowledge. Ecol Monogr 75:3-35

Hoyle RH (2012) Handbook of structural equation modeling

Huston MA (2004) Management strategies for plant invasions: manipulating productivity, disturbance, and competition. Divers Distrib 10:167-178

Kennedy TA, Naeem S, Howe KM et al (2002) Biodiversity as a barrier to ecological invasion. Nature 417:636-638
Knight KS, Reich PB (2005) Opposite relationships between invasibility and native species richness at patch versus landscape scales. Oikos 109:81-88

Laossi K-R, Noguera DC, Bartolomé-Lasa A et al (2009) Effects of an endogeic and an anecic earthworm on the competition between four annual plants and their relative fecundity. Soil Biol Biochem 41:1668-1673

Laossi KR, Noguera DC, Barot S (2010) Earthworm-mediated maternal effects on seed germination and seedling growth in three annual plants. Soil Biol Biochem 42:319-323

Laossi K-R, Noguera DC, Decäens T et al (2011) The effects of earthworms on the demography of annual plant assemblages in a long-term mesocosm experiment. Pedobiologia 54:127-132

Levine JM, D'Antonio CM (1999) Elton revisited: a review of evidence linking diversity and invasibility. Oikos 87:15-26

Lodge DM (1993) Biological invasions-lessons for ecology. Trends Ecol Evol 8:133-137

Loreau M, Hector A (2001) Partitioning selection and complementarity in biodiversity experiments. Nature 412:72-76

Madritch M, Lindroth R (2009) Removal of invasive shrubs reduces exotic earthworm populations. Biol Invasions 11:663-671

McCormick MK, Parker KL, Szlavecz K et al. (2013) Native and exotic earthworms affect orchid seed loss. AoB Plants 5

McRill M, Sagar GR (1973) Earthworms and seeds. Nature 243:482

Milcu A, Paul S, Lukac M (2011) Belowground interactive effects of elevated $\mathrm{CO} 2$, plant diversity and earthworms in grassland microcosms. Basic Appl Ecol 12:600-608

Naeem S, Knops JMH, Tilman D et al (2000) Plant diversity increases resistance to invasion in the absence of covarying extrinsic factors. Oikos 91:97-108

Nuutinen V, Butt KR (2005) Homing ability widens the sphere of influence of the earthworm Lumbricus terrestris L. Soil Biol Biochem 37:805-807

Nuzzo VA, Maerz JC, Blossey B (2009) Earthworm Invasion as the driving force behind plant invasion and community change in Northeastern North American Forests. Conserv Biol 23:966-974

Partsch S, Milcu A, Scheu S (2006) Decomposers (Lumbricidae, Collembola) affect plant performance in model grasslands of different diversity. Ecology 87:2548-2558

Pimentel D, Zuniga R, Morrison D (2005) Update on the environmental and economic costs associated with alien-invasive species in the United States. Ecol Econ 52:273-288

Pyšek P, Jarošík V, Hulme PE et al (2010) Disentangling the role of environmental and human pressures on biological invasions across Europe. Proc Natl Acad Sci 107:12157-12162

Reich PB, Tilman D, Isbell F et al (2012) Impacts of biodiversity loss escalate through time as redundancy fades. Science 336:589-592

Schaefer H, Hechenleitner P, Santos-Guerra A et al (2012) Systematics, biogeography, and character evolution of the legume tribe Fabeae with special focus on the middleAtlantic island lineages. BMC Evol Biol 12:250

Shipitalo MJ, Nuutinen V, Butt KR (2004) Interaction of earthworm burrows and cracks in a clayey, subsurfacedrained, soil. Appl Soil Ecol 26:209-217

Singer FJ, Swank WT, Clebsch EEC (1984) Effects of wild pig rooting in a deciduous forest. J Wildl Manag 48:464-473 
Srivastava DS, Cadotte MW, MacDonald AAM et al (2012) Phylogenetic diversity and the functioning of ecosystems. Ecol Lett 15:637-648

Stohlgren TJ, Jarnevich C, Chong GW et al (2006) Scale and plant invasions: a theory of biotic acceptance. Preslia 78:405-426

R Development Core Team (2009) A language and environment for statistical computing. v2.15.3. ISBN 3-900051-07-0. R Foundation for Statistical Computing. Vienna, Austria

Thompson K, Green A, Jewels AM (1994) Seeds in soil and worm castings from a neutral grassland. Funct Ecol 8:29-35

Thuiller W (2007) Biodiversity: climate change and the ecologist. Nature 448:550-552

Tilman D (1997) Community invasibility, recruitment limitation, and grassland biodiversity. Ecology 78:81-92

Tilman D, Reich PB, Isbell F (2012) Biodiversity impacts ecosystem productivity as much as resources, disturbance, or herbivory. Proc Natl Acad Sci 109:10394-10397
Vitousek PM, Walker LR, Whiteaker LD et al (1987) Biological invasion by Myrica faya Alters ecosystem development in Hawaii. Science 238:802-804

Vitousek PM, D’Antonio CM, Loope LL et al (1996) Biological invasions as global environmental change. Am Sci 84:468-478

Whitfeld TJS, Lodge AG, Roth AM, et al. (2013) Community phylogenetic diversity and abiotic site characteristics influence abundance of the invasive plant Rhamnus cathartica L. J Plant Ecol. doi:10.1093/jpe/rtt020

Wiens JJ, Ackerly DD, Allen AP et al (2010) Niche conservatism as an emerging principle in ecology and conservation biology. Ecol Lett 13:1310-1324

Wurst S, Langel R, Scheu S (2005) Do endogeic earthworms change plant competition? A microcosm study. Plant Soil 271:123-130

Wurst S, Gebhardt K, Rillig MC (2011) Independent effects of arbuscular mycorrhiza and earthworms on plant diversity and newcomer plant establishment. J Veg Sci 22:1021-1030 